\title{
Socio-economic and Demographic Risk Factors for Overweight or Obesity among Ever Married Women in Bangladesh: A Mixed Model Approach
}

\author{
Nasrin Sultana* and Mirajul Islam \\ Department of Statistics, Dhaka University, Dhaka-1000, Dhaka, Bangladesh
}

(Received: 31 January 2019; Accepted: 23 June 2019)

\begin{abstract}
Overweight or obesity has adverse effects on health as the risk of diabetes and cardiovascular disease is very high among overweight or obese women. Even mortality rate among overweight and obese people is more than that of normal or underweight people. The risk of facing adverse maternal and fetal complications during pregnancy, delivery, and postpartum is higher among overweight/obese women. In Bangladesh, the percentage of overweight/obesity among ever married women which was only 9 percent in 2004 was found to be 24 percent in 2014. The main purpose of the study is to determine the responsible factors for the overweight or obesity among ever married women aged 15-49 years in Bangladesh. Data have been taken out from Bangladesh Demographic and Health Survey (BDHS), 2014 to serve this purpose. Since there are 600 clusters in BDHS data, cluster effects are taken into account to find the estimates of the regression parameters by applying mixed logistic regression model. The results obtained from the model show that women from poor family (OR $=0.69)$, living in Rangpur $(\mathrm{OR}=0.83)$ and Sylhet regions $(\mathrm{OR}=0.66)$, currently working $(\mathrm{OR}=0.79)$ and using modern contraceptive $(\mathrm{OR}=0.88)$ are significantly less overweight/obese than women from middle class family, living in Dhaka region, currently not working and using contraceptive except modern type, respectively. On the other hand, women from urban residence $(\mathrm{OR}=1.54)$, having education and educated husband, women from rich family $(\mathrm{OR}=1.63)$, married women $(\mathrm{OR}=1.48)$, older age, watching TV at least once in a week $(\mathrm{OR}=1.35)$ and having two or three ever born children $(\mathrm{OR}=1.31)$ are more overweight/obese than their respective counterpart.
\end{abstract}

Keywords: BMI, overweight, obesity, BDHS, cluster, mixed logistic regression.

\section{Introduction}

The prevalence of obesity is increasing day by day all over the world. The number of obese people in the world was more than 600 million in $2014^{1}$. In many developed countries, obesity has been declared as epidemic ${ }^{2,3}$. Moreover, this increasing trend of obesity is also observed in low or middle income countries.

In low income countries, rapid urbanization and industrialization are responsible for the change in food habits and these changes are leading to nutritional transition $^{4,5}$. In Bangladesh, the number of overweight and obese adults is increasing significantly. According to BDHS report-2014, the percentage of overweight or obesity among ever-married women in Bangladesh aged 15-49 has been increased from $9 \%$ in 2004 to $24 \%$ in 2014and this percentage is 39 based on the classification provided by the WHO Expert Consultation in $2004^{6}$.

Overweight and obese women suffer from various health problems. Besides, high pre-pregnancy body mass index (BMI) among women can be responsible for poor maternal and birth outcomes. These abnormal BMIs can lead to adverse maternal and fetal complications during pregnancy, delivery, and postpartum ${ }^{7}$. Obese women face more induction of labor, cesarean delivery, post-dated pregnancy and postpartum complications than others ${ }^{8}$. Vertebral fracture was found higher among overweight or obese women than normal and underweight women ${ }^{9}$. Moreover, the risk of childhood, adolescence and adulthood obesity increases if the mothers of these children are obese ${ }^{10}$. In addition to this, several diseases such as hypertension, diabetes, high cholesterol, heart disease, stroke, arthritis and cancer may occur due to obesity $^{11}$. It was also found that depression and obesity are associated $^{12}$. Even mortality was found to be positively correlated with the increase in BMI of both women and men in a study conducted by American Cancer Society Cohort $^{13}$. Moreover, the risk of postmenopausal breast as well as endometrial cancers is gradually increased by obesity $^{14}$. It was found in several studies that overweight and obese people have to take more medical care than those people having normal weight ${ }^{15-17}$. From the above studies, it can be easily concluded that overweight or obese women are at high risk of facing serious problems and the condition of overweight or obese women are becoming worse day by day in Bangladesh. Therefore, it is high time to find out which variables have impacts on obesity in Bangladesh.

Among the currently non-pregnant married women in Bangladesh, BMI was found to be positively associated with the education level of the women and their husbands, increase in age, wealth index, age at first marriage and age at first delivery ${ }^{18}$. Besides, overweight or obesity among women in Myanmar was observed to be positively associated with residence type, economic status, regions, contraceptive use, living with a partner, number of children everborn $^{19}$. On the other hand, tobacco use among the adult women was found to be negatively associated with overweight or obesity. Moreover, obesity was observed to have association with a higher carbohydrate and fibre intake $^{20}$.

Considering the harmful effects of overweight or obesity, the purpose of the study is to find out the factors which are responsible for increasing overweight or obesity in Bangladesh. To do this, the nationally representative BDHS, 2014 data have been used. Since this data consist of 
600 clusters, mixed logistic regression model has been applied to find the better estimates of the regression parameters by taking into account the effects of cluster as random effects.

\section{Data and Methods}

Data for this research work have been taken out from Bangladesh Demographic Health Survey (BDHS), 2014. A two-stage stratified sampling technique was performed in this survey: six hundred enumeration areas (EAs) were selected based on probability proportional to the size of EA in the first stage and for each EA, on average thirty households were selected based on systematic sampling in the second stage with a view to providing statistically authentic estimates of leading demographic as well as health related variables for the whole country. In this study, only women who are not currently pregnant as well as do not give birth preceding two months of the survey have been considered among the all ever married women aged 15-49. After deleting missing cases, the desired dataset consisting of 16315 observations has been got ready for analysis.

\section{Outcome variable}

To serve the purpose of this study, overweight or obesity has been selected as the response variable of interest which is created from the available information on BMI (body mass index). According to the worldwide classification, women whose BMI is greater or equal to $25 \mathrm{~kg} / \mathrm{cm}^{2}$ are considered to be overweight or obese.

\section{Regressor variables}

Based on some literature reviews, a bunch of regressor variables such as region, residence type, religion, education, current age, marital status, age at first marriage, wealth index, husband/partner's education, type of contraceptive method use, current working status and watching television at least once in a week have been considered in the study. Some of these explanatory variables have been recoded into the convenient categories for the sake of analysis as well as easier interpretation.

\section{Regression model}

In this study, generalized linear mixed model (GLMM) has been applied to consider the correlation among the observations within each cluster. That is, random effects has been included with fixed effects to obtain more precise estimates of the regression parameters than generalized linear model.

Let $Y_{i j}$ be the $j^{\text {th }}$ observation in the $i^{\text {th }}$ cluster where $i=1,2, \ldots, m$ and $j=1,2, \ldots, n_{i}$ and $\pi_{i j}$ be the probability that $y_{i j}=1$. Then, $Y_{i j}$ 's are randomly distributed as: $y_{i j} \mid \pi_{i j} \sim \operatorname{binomial}\left(1, \pi_{i j}\right)$. Therefore, logistic regression model with random intercept term can be written as-

$$
\log \left(\frac{\pi_{i j}}{1-\pi_{i j}}\right)=X_{i j}^{\prime} \beta+u_{i}
$$

where $u_{i}$ is the random intercept term, $X_{i j}$ is the vector of covariates associated with the individual having outcome $Y_{i j}$ and $\beta$ is the vector of regression parameters.

\section{Results and Discussion}

\section{Bivariate findings}

In the Table 01, cross tabulation between the overweight/obesity response variable and various explanatory variables along with row percentage have been presented. In addition to this, the $p$-values for chisquare test of independence are also shown in this table. From the row percentage of overweight or obese women, it can be said that the highest percentage of overweight or obese women is found in Khulna whereas the lowest percentage is in Sylhet. Again, urban areas have higher percentage of overweight/obese women than the rural areas. Moreover, higher educated women are mostly overweight or obese $(40.8 \%)$ whereas women who have no education are rarely overweight or obese (16.8\%). Furthermore, rich family has the highest percentage of overweight or obese women while poor family has the lowest percentage.

It is also observed that higher educated husbands/partners have the highest percentage overweight or obese wives whereas husbands/partners having no education have the lowest percentage overweight or obese wives. Again, women who are currently unemployed are found to be more overweight/obese $(26.1 \%)$ than those who are currently working anywhere $(21.5 \%)$. Moreover, married women are found to have the highest percentage of being overweight/obese while separated women are found to have the lowest percentage of being overweight or obese. Women aged thirty to thirty nine are the most overweight/obese $(30.7 \%)$ whereas teenage women are the least overweight or obese $(7.3 \%)$. The percentage of overweight/obesity among the women who first married at age older than eighteen is higher than that among the women getting married at age eighteen or earlier. Interestingly, women who watch television at least once in a week have higher percentage of being overweight/obese than those who watch television less than once in a week. Women having two to three children are found to have the highest percentage of being overweight/obese whereas women having no children have the lowest percentage of being overweight or obese. Furthermore, the percentage of overweight/obese women is the highest for women who use traditional contraceptive method whereas it is the lowest for women who use folkloric contraceptive method.Observing the $p$-value corresponding to each of the covariates from the Table 01, it is clear that all variables except religion are significantly associated with the response variable overweight or obese. 
Table 1. Percentage of overweight or obese respondents by background characteristics along with p-values for chisquare test

\begin{tabular}{|c|c|c|c|c|}
\hline \multirow[t]{2}{*}{ Covariates } & & \multicolumn{2}{|c|}{ Overweight or Obese } & \multirow[t]{2}{*}{ p-value } \\
\hline & & $\frac{\text { Yes }}{\mathrm{n}(\%)}$ & $\mathrm{n} \frac{\mathrm{No}}{(\%)}$ & \\
\hline \multirow[t]{7}{*}{ Region } & Barisal & $406(21.0)$ & $1529(79.0)$ & $<0.001$ \\
\hline & Chittagong & $734(28.4)$ & $1850(71.6)$ & \\
\hline & Dhaka & $802(28.2)$ & $2046(71.8)$ & \\
\hline & Khulna & $708(29.2)$ & $1715(70.8)$ & \\
\hline & Rajshahi & $597(25.4)$ & 1749 (74.6) & \\
\hline & Rangpur & $445(19.0)$ & $1900(81.0)$ & \\
\hline & Sylhet & $318(17.3)$ & $1516(82.7)$ & \\
\hline \multirow[t]{2}{*}{ Residence type } & Urban & $2040(35.9)$ & $3637(64.1)$ & $<0.001$ \\
\hline & Rural & $1970(18.5)$ & $8668(81.5)$ & \\
\hline \multirow[t]{4}{*}{ Education level } & No education & $670(16.8)$ & $3330(83.2)$ & $<0.001$ \\
\hline & Primary & $1012(21.1)$ & 3773 (78.9) & \\
\hline & Secondary & $1711(28.4)$ & 4307 (71.6) & \\
\hline & Higher & $617(40.8)$ & $895(59.2)$ & \\
\hline \multirow[t]{2}{*}{ Religion } & Muslim & $3637(24.7)$ & $11084(75.3)$ & 0.250 \\
\hline & Non-muslim & $373(23.4)$ & $1221(76.6)$ & \\
\hline \multirow[t]{3}{*}{ Wealth index } & Poor & $669(11.2)$ & $5308(88.8)$ & $<0.001$ \\
\hline & Middle & $658(19.8)$ & $2658(80.2)$ & \\
\hline & Rich & $2683(38.2)$ & $4339(61.8)$ & \\
\hline \multirow[t]{4}{*}{ Husband's education level } & No education & $722(15.4)$ & $3980(84.6)$ & $<0.001$ \\
\hline & Primary & $894(20.3)$ & $3519(79.7)$ & \\
\hline & Secondary & $1359(28.4)$ & $3418(71.6)$ & \\
\hline & Higher & $1035(42.7)$ & $1388(57.3)$ & \\
\hline \multirow[t]{2}{*}{ Currently working } & Yes & $1151(21.5)$ & $4198(78.5)$ & $<0.001$ \\
\hline & No & $2859(26.1)$ & $8107(73.9)$ & \\
\hline \multirow[t]{3}{*}{ Marital status } & Married & $3818(24.9)$ & $11486(75.1)$ & $<0.001$ \\
\hline & wed/Divorced & $155(19.9)$ & $624(80.1)$ & \\
\hline & Separated & $37(15.9)$ & $195(84.1)$ & \\
\hline \multirow[t]{4}{*}{ Current age } & $<20$ & $115(7.3)$ & $1466(92.7)$ & $<0.001$ \\
\hline & $20-29$ & $1189(21.0)$ & $4482(79.0)$ & \\
\hline & $30-39$ & $1578(30.7)$ & $3561(69.3)$ & \\
\hline & $>=40$ & $1128(28.7)$ & $2796(71.3)$ & \\
\hline Age at first marriage & $<=18$ & $3267(23.0)$ & $10924(77.0)$ & $<0.001$ \\
\hline$>18$ & & $743(35.0)$ & $1381(65.0)$ & \\
\hline \multirow[t]{2}{*}{ Watching TV at least once in a week } & Yes & $2832(33.4)$ & $5639(66.6)$ & $<0.001$ \\
\hline & No & $1178(15.0)$ & $6666(85.0)$ & \\
\hline \multirow[t]{4}{*}{ Children ever born } & No child & $209(16.1)$ & $1089(83.9)$ & $<0.001$ \\
\hline & One & 759 (21.7) & $2739(78.3)$ & \\
\hline & Two to three & $2193(28.9)$ & $5398(71.1)$ & \\
\hline & Above three & 849 (21.6) & $379(78.4)$ & \\
\hline \multirow[t]{4}{*}{ Type of contraceptive use } & No method & $1454(24.4)$ & $4507(75.6)$ & $<0.001$ \\
\hline & Folkloric & $06(22.2)$ & $21(77.8)$ & \\
\hline & Traditional & $416(32.3)$ & $870(67.7)$ & \\
\hline & Modern & 2134 (23.6) & $6907(76.4)$ & \\
\hline
\end{tabular}


That is, respondent's region, residence type, education level, economic status, husband's education, marital status, working status, current age, age at first marriage, watching $\mathrm{TV}$ at least once in a week, children ever born and type of contraceptive use are highly ( $p$-value $<0.001)$ significantly associated with the response overweight or obesity.

\section{Regression findings}

The variables which are found to have significant association with the overweight or obesity response variable in the bivariate analysis are only taken into account in the regression model. Since the data were clustered data, a mixed logistic regression analysis has been performed with a view to considering the cluster effect. The results obtained from the regression model have been shown in the Table 02. For easier interpretation, odds ratio (OR) has been calculated for each of the covariates along with the corresponding 95\% confidence interval (C.I). From the Table 02 , it is observed that all the covariates considered in the regression model except age at first marriage have statistically significant effect on the overweight/obese response variable. Among these covariates, education, partner's education, wealth status, marital status, current age, watching TV and children ever born have positive significant effect on the overweight or obese response while current working status and type of contraceptive method use have negative significant effect on the response variable that is overweight/obesity. To be more specific, the odds of overweight/obesity among ever married women being currently non-pregnant and not giving birth within two months preceding the survey is 23\% [OR $=1.23,95 \%$ C.I. $=(1.03,1.44)]$ higher in Khulna while $17 \%$ and $34 \%$ less in Rangpur and Sylhet, respectively compared to that in Dhaka region. It implies that there exists significant regional difference which needs to be reduced in order to decrease the prevalence rate of overweight/obesity. Again, the odds of overweight or obesity is 54\% higher among the women in urban areas than that in rural areas. Moreover, the odds of overweight/obesity for women increases with the increase in their education level as well as in their husband's education level. Women with primary, secondary and higher education have $26 \%, 49 \%$ and $52 \%$ greater odds of being overweight or obese respectively than those having no education. Again, primary, secondary and higher educated husbands' wives have $18 \%, 37 \%$ and $74 \%$ greater odds of overweight or obesity accordingly compared to the wives whose husbands have no education.

Furthermore, the odds of overweight or obesity increases with the increase in wealth index. That is, women in poor family have $31 \%$ less odds of being overweight/obese while women in rich family have $63 \%$ higher odds of being overweight/obese than those in middle class family. It is also found that the odds of overweight or obesity is $21 \%$ less among the women who are currently working than that of the unemployed women. Moreover, currently married women have $48 \%$ higher odds of being overweight/obese than widowed/divorced women whereas odds of overweight or obesity does not significantly differ between the currently widowed/divorced women and separated women. Furthermore, the odds of overweight/obesity is much higher for women aged 20 to 29 years $(\mathrm{OR}=3.28), 30$ to 39 years $(\mathrm{OR}=6.58)$ and greater than 39 years $(\mathrm{OR}=6.39)$ compared to that for teenage women. In this case, biological factors may be related with the age of women which may contribute to this higher odds of getting overweight or obese for older women.

Moreover, watching television at least once in a week has also highly significant ( $p$-value $<0.001)$ effect on the overweight/ obesity such that women who watch TV minimum once in a week have $35 \%$ higher odds of being overweight or obese than those who do not. This may happen due to less physical movement of the women during watching television. Again, the odds of overweight/ obesity among women having two or three children ever born is $31 \%$ higher than that of women having no child while the women having no child, one child and more than three children ever born have equal odds of being overweight/ obese at $5 \%$ level of significance.

Additionally, it can be said that women who are currently using modern contraceptive method have $12 \%$ less odds of being overweight or obese than those who do not use any method.

Table 2. Estimates of regression coefficients along with p-value and odds ratios along with $95 \%$ confidence interval (C.I.)

\begin{tabular}{lrcccc}
\hline Covariates & & Estimate & p-value & OR & 95\% C.I. of OR \\
\hline Region & Barisal & -0.16 & 0.084 & 0.85 & $(0.69,1.01)$ \\
& Chittagong & 0.10 & 0.243 & 1.10 & $(0.92,1.28)$ \\
Dhaka (Ref.) & - & - & - & - \\
& Khulna & 0.21 & 0.011 & 1.23 & $(1.03,1.44)$ \\
& Rajshahi & 0.05 & 0.522 & 1.06 & $(0.88,1.23)$ \\
& Rangpur & -0.18 & 0.043 & 0.83 & $(0.69,0.98)$ \\
Residence type & Sylhet & -0.41 & $<0.001$ & 0.66 & $(0.54,0.79)$ \\
& Urban & 0.43 & $<0.001$ & 1.54 & $(1.38,1.71)$ \\
Education level & Rural (Ref.) & - & - & - & - \\
& No education (Ref.) & - & - & - & - \\
& Primary & 0.23 & $<0.001$ & 1.26 & $(1.10,1.41)$
\end{tabular}




\begin{tabular}{|c|c|c|c|c|c|}
\hline & Secondary & 0.40 & $<0.001$ & 1.49 & $(1.29,1.70)$ \\
\hline & Higher & 0.42 & $<0.001$ & 1.52 & $(1.21,1.83)$ \\
\hline \multirow[t]{3}{*}{ Wealth index } & Poor & -0.37 & $<0.001$ & 0.69 & $(0.60,0.78)$ \\
\hline & Middle (Ref.) & - & - & - & - \\
\hline & $\begin{array}{r}\text { Rich } \\
\text { R }\end{array}$ & 0.49 & $<0.001$ & 1.63 & $(1.44,1.81)$ \\
\hline \multirow{4}{*}{ Husband's education } & No education (Ref.) & - & - & - & - \\
\hline & Primary & 0.16 & 0.008 & 1.18 & $(1.03,1.32)$ \\
\hline & Secondary & 0.31 & $<0.001$ & 1.37 & $(1.19,1.54)$ \\
\hline & Higher & 0.55 & $<0.001$ & 1.74 & $(1.45,2.02)$ \\
\hline \multirow[t]{2}{*}{ Currently working } & Yes & -0.24 & $<0.001$ & 0.79 & $(0.72,0.86)$ \\
\hline & No (Ref.) & - & - & - & - \\
\hline \multirow[t]{3}{*}{ Marital status } & Married & 0.39 & $<0.001$ & 1.48 & $(1.18,1.79)$ \\
\hline & Vidowed/Divorced (Ref.) & - & - & - & - \\
\hline & Separated & -0.03 & 0.876 & 0.97 & $(0.56,1.37)$ \\
\hline \multirow{4}{*}{ Current age } & $<20$ (Ref.) & - & - & - & - \\
\hline & $20-29$ & 1.19 & $<0.001$ & 3.28 & $(2.55,4.01)$ \\
\hline & $30-39$ & 1.88 & $<0.001$ & 6.58 & $(5.01,8.15)$ \\
\hline & $>=40$ & 1.86 & $<0.001$ & 6.39 & $(4.78,8.01)$ \\
\hline \multirow[t]{2}{*}{ Age at first marriage } & $<=18$ (Ref.) & - & - & - & - \\
\hline & $>18$ & -0.04 & 0.501 & 0.96 & $(0.84,1.08)$ \\
\hline \multirow[t]{2}{*}{ Watching TV } & Yes & 0.30 & $<0.001$ & 1.35 & $(1.21,1.48)$ \\
\hline & No (Ref.) & - & - & - & - \\
\hline \multirow[t]{4}{*}{ Children ever born } & No child (Ref.) & - & - & - & - \\
\hline & One & 0.10 & 0.305 & 1.11 & $(0.89,1.31)$ \\
\hline & Two to three & 0.27 & 0.007 & 1.31 & $(1.05,1.57)$ \\
\hline & Above three & 0.13 & 0.269 & 1.13 & $(0.88,1.39)$ \\
\hline \multirow[t]{4}{*}{ Type of contraceptive use } & No method (Ref.) & - & - & - & - \\
\hline & Folkloric & -0.46 & 0.353 & 0.63 & $(0.02,1.24)$ \\
\hline & Traditional & 0.09 & 0.233 & 1.10 & $(0.93,1.26)$ \\
\hline & Modern & -0.12 & 0.011 & 0.88 & $(0.80,0.97)$ \\
\hline -2Log likelihood & & \multicolumn{2}{|c|}{15750.8} & & \\
\hline \multicolumn{2}{|l|}{ Variance component } & \multicolumn{2}{|c|}{0.1032} & & \\
\hline
\end{tabular}

It indicates that modern method of contraceptive use is quite useful for women to be away from being overweight or obese. In fact, the odds of being overweight/ obese do no differ among the women who are using folkloric or traditional method and women who are not using any contraceptive method at al.

\section{Conclusion}

Despite the progress in reducing underweight women, overweight or obesity are becoming serious matter of concern in Bangladesh. The rate of prevalence of overweight/obesity among ever married women in this country is found as $24.6 \%$ in our study. These overweight/obese women are at high risk of suffering from various diseases such as diabetes, hypertension, heart disease, stroke etc. So, it has become crucial need to find the responsible factors of overweight and obesity in Bangladesh. In this study, statistical analysis has been performed on the data obtained from BDHS, 2014 to determine those factors. The factors associated with overweight or obesity are found out which will help the policy makers to take necessary steps so that noncommunicable diseases resulted from overweight/obesity can be prevented by improving the health condition of women in Bangladesh.

\section{References}

1. WHO Global InfoBase- data and analysis of overweight and obesity, Fact sheet N0, 311, updated on January 2015.

2. Hill JO, JC Peters, 1998. Environmental contributions to the obesity epidemic. Science. 280 (5368), 1371-1374.

3. James PT, R. Leach, E. Kalamara, M. Shayeghi, 2001. The worldwide obesity epidemic. Obesity Reviews. 9 (S11), 228S-233S.

4. Monteiro CA, WL Conde, BM Popkin, 2004. The burden of disease from under nutrition and over nutrition in countries undergoing rapid nutrition transition: a view from Brazil. Am J Public Health. 94(3), 433-434.

5. Popkin BM, 1994. The Nutrition Transition in Low Income Countries: An Emerging Crisis. Nutrition Reviews. 52 (9), 285-298.

6. Bangladesh Demographic and Health Survey (BDHS), 2014. National Institute of Population Research and Training (NIPORT) of the Ministry of Health and Family Welfare. ICF International of Rockville, Maryland, USA and Dhaka, NIPORT, Mitra and Associates.

7. Van Lieshout R. J., V. H. Taylor, and M. H. Boyle, 2011. Pre-pregnancy and pregnancy obesity and neurodevelopmental 
outcomes in off spring: a systematic review. Obesity Reviews. 12(5), e548-59.

8. Agrawal S., A. Singh, 2016. Obesity or Underweight-What is Worse in Pregnancy? The Journal of Obstetrics and Gynecology of India. 66(6), 448-452.

9. Tanaka S., T. Kuroda, M. Saito and M. Shiraki, 2013. Overweight/obesity and underweight are both risk factors for osteoporotic fractures at different sites in Japanese postmenopausal women. Osteoporos Int. 24,69-76.

10. Black, R. E. et al., 2013. Maternal and Child Under nutrition and Overweight in Low-Income and Middle-Income Countries. The Lancet.382(9890), 427-51.

11. Flegal KM, MD Carroll, CL Ogden and LR Curtin, 2010. Prevalence and Trends in Obesity among US adults, 1992008. JAMA. 303, 235-41.

12. Teresa Kulie, MD et al., 2011. Obesity and Women's Health: An Evidence-Based Review. Clinical Review, JABFM.24(1), 75-85. doi: 10.3122/jabfm.2011.01.100076

13. Stevens J., J. Cai, ER Pamuk, DF Williamson, MJ Thun, JL Wood, 1998. The effect of age on the association between body mass index and mortality. N Engl J Med. 338(1), 1-7.

14. Frank B. H., 2003.Overweight and Obesity in Women: Health Risks and Consequences. Journal of Women's Health. 12(2), 163-72.
15. Kuriyama S., I. Tsuji, T. Ohkubo et al., 2002. Medical care expenditure associated with body mass index in Japan: the Ohsaki Study. Int J ObesRelatMetabDisord. 26(8),1069-74.

16. Thompson D., J.B. Brown, G.A. Nichols et al., 2001. Body mass index and future healthcare costs: a retrospective cohort study. Obes Res. 9(3), 210-18.

17. Quesenberry CP Jr, B. Caan, A. Jacobson, 1998. Obesity, health services use, and health care costs among members of a health maintenance organization. Arch Intern Med. 158,466-72.

18. Hossain, M.G., P. Bharati, S. AIk, P. E. Lestrel, A. Abeer and T. Kamrul, 2012. Body Mass Index of Married Bangladeshi Women: Trends and Association with Socio-Demographic Factors. J. Biosoc. Sci.44(4),385-99.

19. Hong S. A., K. Peltzer, K. T. Lwin, L. S. Aung, 2018. The prevalence of underweight, overweight and obesity and their related socio-demographic and lifestyle factors among adult women in Myanmar, 2015-16. PLoS ONE 13(3), e0194454.

20. Duvigneaud N., K. Wijndaele, L. Matton, R. Philippaerts, J. Lefevre, M. Thomis, C. Delecluse and W. Duquet, 2007. Dietary factors associated with obesity indicators and level of sports participation in Flemish adults: a cross-sectional study. BMC Nutrition Journal. 6, 26. 